\title{
ENSINO SUPERIOR E EMPREGABILIDADE: PERCEÇÕES DE ESTUDANTES E GRADUADOS, EMPREGADORES E ACADÊMICOS*
}

\author{
António Fragoso ${ }^{1}$ (1) \\ SANDRA T. VALADAS ${ }^{1}$ (D) \\ Liliana Paulos ${ }^{2}$ (D)
}

\begin{abstract}
RESUMO: Neste artigo pretendemos refletir criticamente sobre os significados da empregabilidade e o papel que o ensino superior (ES) poderá ter na sua promoção. Analisamos dados de um projeto europeu considerando as perceçôes de estudantes e graduados, empregadores e acadêmicos. Os resultados mostram que estudantes, graduados e empregadores internalizaram uma visão dominante de empregabilidade (contrariamente aos acadêmicos) que implica considerar o ES como responsável pela empregabilidade. Indicam, também, que para os acadêmicos é crucial a ideia de que as instituiçóes de ES não devem estar ao serviço do mercado de trabalho, mas sim das sociedades. Os grupos inquiridos estáo de acordo em que apoiar os estudantes na transiçáo para o emprego é um objetivo instrumental importante.
\end{abstract}

Palavras-chave: Ensino superior. Empregabilidade. Graduados. Empregadores. Comunidade acadêmica.

\section{HIGHER EDUCATION AND EMPLOYABILITY: PERCEPTIONS OF STUDENTS AND GRADUATES, EMPLOYERS AND ACADEMIC STAFF}

ABSTRACT: In this article, we intend to reflect critically on the meanings of employability and the role that higher education (HE) can have on its promotion. We analysed data from a European project, considering the perceptions of students and graduates, employers and academics. The results show that students, graduates and employers have internalized a dominant vision of employability (contrarily to the academic staff) that considers $\mathrm{HE}$ as its main responsible. For the academic staff, HE institutions should not be at the service of the labour market, but of societies. The groups surveyed agree that supporting students in the transition to employment is a crucial goal.

Keywords: Higher education. Employability. Graduates. Employers. Academic staff.

\footnotetext{
*Este artigo é resultado do projeto de pesquisa EMPLOY, 2014-1-UK01-KA203-001842-T, "Enhancing the employability of non-traditional students in Higher Education", financiado pelo programa Erasmus+. ${ }^{1}$ Universidade do Algarve, Centro de Investigação sobre o Espaço e as Organizaçôes - Faro, Portugal.

E-mails: aalmeida@ualg.pt; svaladas@ualg.pt

${ }^{2}$ Universidade do Minho, Centro de Investigação em Educação - Braga, Portugal.

E-mail: lilianasspaulos@gmail.com

DOI: 10.1590/ES0101-73302019186612
}

Educ. Soc., Campinas, v.40, e0186612, 2019 


\title{
ENSEÑANZA SUPERIOR Y EMPLEABILIDAD: PERCEPCIONES DE ESTUDIANTES Y GRADUADOS, EMPLEADORES Y ACADÉMICOS
}

\begin{abstract}
RESUMEN: En este artículo pretendemos reflexionar críticamente sobre los significados de la empleabilidad y el papel que la enseñanza superior (ES) podrá tener en su promoción. Analizamos datos de un proyecto europeo considerando las percepciones de estudiantes y graduados, empleadores y académicos. Los resultados muestran que estudiantes, graduados y empleadores internalizaron una visión dominante de empleabilidad (contrariamente a los académicos) que implica considerar el ES como responsable por la empleabilidad. Indican, también, que para los académicos es crucial la idea de que las instituciones de ES no deben estar al servicio del mercado de trabajo, pero sí de las sociedades. Los grupos inquiridos están de acuerdo en que apoyar a los estudiantes en la transición para el empleo es un objetivo instrumental importante.
\end{abstract}

Palabras clave: Enseñanza superior. Empleabilidad. Graduados. Empleadores. Comunidad académica.

\section{Introdução}

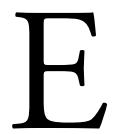

m um relatório recente, a Comissão Europeia (2014) agregou, pela primeira vez, os conceitos de acesso, retenção e empregabilidade, revelando uma mudança importante nas políticas europeias: as Instituiçóes de Ensino Superior (IES) deveriam responder às necessidades do mercado de trabalho. O relatório evidencia que utilizar as informaçóes sobre o mercado de trabalho, de forma sistemática, para planificar as políticas do Ensino Superior (ES), é relativamente raro nos países Europeus. Existem outras áreas em que os incentivos dos estados europeus são uma realidade e muitos países dão incentivos financeiros a IES e empregadores para aumentar o número de estágios disponíveis a estudantes e diplomados. Surgem, também, generalizados serviços de apoio à empregabilidade destinados a estudantes durante o ES. As exceções, nesse aspecto (COMISSÃO EUROPEIA, 2014), são República Checa, Letônia, Portugal, Croácia e Malta.

Apesar dessa tendência recente, têm sido escassos os estudos que abordam, de forma crítica, a relação entre o ES e a empregabilidade. Mas o que é a empregabilidade? Devem as universidades promover a empregabilidade? Que tipos de relaçóes devem as IES estabelecer com os empregadores? É possível apoiar estudantes e diplomados melhorando a sua empregabilidade? 
São diversas as conceçóes sobre empregabilidade que encontramos na literatura. No âmbito desse artigo abordamos, sobretudo, as perspetivas dominantes do conceito. Uma delas vem na continuidade das teorias do capital humano: a educação superior seria um investimento capaz de produzir uma força de trabalho altamente qualificada que, não só daria os seus contributos para o crescimento econômico, como produziria retornos individuais a partir do investimento realizado - salariais e em termos de progressão profissional, entre outros. Nessa lógica, a formação superior deveria promover a procura por melhores empregos, aumentar o crescimento econômico e estimular a empregabilidade (MAYHEW \& KEEP, 1999).

Para refletir sobre as questóes associadas à empregabilidade e ao papel do ES nessa equação, recorremos aos resultados da investigação realizada nos últimos três anos no contexto de um projeto europeu. O projeto EMPLOY ${ }^{1}$ pretende melhorar a empregabilidade de estudantes e diplomados do ES, considerando as perceções de três grupos de atores sociais: os estudantes e graduados em transição para o emprego, o staff acadêmico e os empregadores. Nesse artigo refletimos sobre os dados relativos a Portugal, cujo enquadramento se segue.

\section{O contexto português: ensino superior e empregabilidade}

Em Portugal, um conjunto alargado de fatores tem empurrado o ES para o centro do debate sobre a empregabilidade. Isso ocorre desde uma certa desvalorização dos diplomas superiores pelo mercado de trabalho, o que vem questionar, de forma abrangente, a relação entre a educação e o emprego. As teorias do capital humano, criadas por Schultz no início dos anos 1960, afirmaram que essa relação era linear: a economia cresceria na medida em que as sociedades eram capazes de fazer investimentos na educação ou, de outra forma, os investimentos na aprendizagem dariam origem, forçosamente, a retornos significativos, tanto individuais (por exemplo, em termos salariais) como societais (SCHULTZ, 1961). Contudo, o advento do neoliberalismo, a evolução dos mercados e da economia, além da própria massificação do ES a que muitos países assistiram, colocaram em causa a linearidade dessa relação - nomeadamente entre o aumento de qualificações e o crescimento econômico. Ademais, o aumento de adultos frequentando cursos de aprendizagem não encontrava equivalência nas oportunidades de emprego, nem mesmo quando se tratava de conhecimentos relacionados com o trabalho, o que começou a produzir uma situação de subemprego (LIVINGSTONE, 1997). Nesse sentido, também o aumento nas credenciais não implicava uma procura econômica acrescida para uma mão-de-obra mais qualificada (TOMLINSON, 2008). Nesse contexto, devemos lembrar que os fatores estruturais - classe social, gênero, minoria cultural etc. - podem funcionar como constrangimentos à mobilidade social. 
Por exemplo, contrariamente às classes trabalhadoras, as classes médias assumem uma vantagem posicional perante o mercado de trabalho utilizando recursos como o capital social (FIELD, 2004) para um acesso privilegiado ao emprego.

A propósito da desvalorização dos diplomas, há evidências que demonstram que os empregadores atribuem cada vez menos importância aos graus acadêmicos (BROWN \& HESKETH, 2004). No passado, um diploma superior representava uma garantia de emprego e a possibilidade de atingir as posiçóes mais elevadas em termos de carreira profissional. A ausência dessa relaçáo quase direta veio transformar a questão do emprego graduado em um problema social e político (ALVES, 2009). O ES foi sendo arrastado para o centro de um debate que envolve um conjunto alargado de atores sociais: estudantes, graduados e famílias, políticos, sindicatos ou os media. Também "governos e empresários esperam que a universidade forme técnicos altamente qualificados e quadros superiores capazes de intervirem de forma competitiva e eficaz no mercado de trabalho" (CABRITO, 2004, p. 978). Mais recentemente, começaram a levantar-se dúvidas em relação a essas expectativas: por exemplo, sobre a eficiência formativa do ES e a sua eficácia em conduzir os graduados aos níveis de empregabilidade desejados (SARRICO et al., 2013). Em alguns discursos, as dificuldades dos graduados em encontrar empregos deixaram de ser atribuídas a causas estruturais. Em vez disso, responsabilizou-se o ES pela falta de qualificaçóes profissionais dos graduados, pelos desencontros entre a oferta acadêmica e a procura do mercado de trabalho e os empregadores alegam que os diplomados não saem do ES com as competências necessárias para trabalhar. Todos esses constrangimentos passaram a ser imputados ao ES em Portugal (ALVES, 2007) e, nessa reflexão, não podemos deixar de fazer referência às implicações de Bolonha.

O processo de Bolonha constituiu um marco indelével que transformou de forma profunda o espaço europeu de ES. Embora sejam múltiplos os objetivos (explícitos ou implícitos) dessa reforma (MORGADO, 2009), não há dúvidas de que a empregabilidade dos cidadãos europeus é um deles. Em Portugal, a implementação do processo de Bolonha (a partir de 2006) colocou a empregabilidade na agenda das instituiçóes de ES (SIN \& AMARAL, 2017), sobretudo porque implicou a entrada em funcionamento do novo Regime Jurídico das Instituiçóes de Ensino Superior (RJIES), que alterou radicalmente os corpos de gestão e funcionamento da comunidade acadêmica. Com o RJIES, o estado português responsabilizou as IES por três funções cruciais (CHAVES \& GAIO Alves, 2014): a promoção de uma melhor cooperação entre a academia e o mercado de trabalho, o apoio direto à inserção profissional dos graduados no mercado de trabalho e a promoção e disseminação de dados comparáveis do emprego graduado e das trajetórias profissionais dos graduados. A partir disso, a ligação entre o ES e a empregabilidade passou a ser uma realidade, entrando no debate público, talvez mesmo antes de o próprio ES perceber as consequências dessa ligação. Em suma, estamos assistindo a uma mudança significativa: deixamos de discutir o emprego, desem- 
prego e subemprego, para discutirmos a empregabilidade. Essa mudança obriga, assim, a uma breve reflexão crítica sobre os significados do conceito.

\section{Uma breve visão crítica de empregabilidade}

Possuir um grau acadêmico funciona cada vez menos como fator diferenciador no acesso ao emprego. Vários estudos apontam para a evidência de que os empregadores estáo crescentemente interessados em outro tipo de competências pessoais e sociais (GAIO ALVES, 2008; BROWN \& HESKETH, 2004). As antigas credenciais, por si, pouco contam diante da personalidade e das soft skills dos graduados (MOREAU \& LEATHWOOD, 2006).

Existem muitas definições e perspetivas diferentes sobre o conceito de empregabilidade, algumas centradas em uma tendência preocupante, a da individualização ante o mercado de trabalho, que aparece nas definições dominantes do conceito: a empregabilidade consistiria na capacidade de os graduados adquirirem competências individuais que, em teoria, os preparariam melhor para o trabalho. Nesse sentido, incluiria não só a capacidade de um graduado conseguir o primeiro emprego mas, também, de mantê-lo ou obter um novo emprego (HILLAGE \& POLLARD, 1998) graças às suas competências e atributos pessoais (YORKE, 2004a): por exemplo, adaptabilidade, capacidade de iniciativa ou autoconfiança, para além de competências processuais, como a capacidade de resolução de conflitos, a resolução de problemas ou a tomada de decisóes (YORKE \& KNIGHT, 2006). Essa individualização dos graduados perante o mercado de trabalho neoliberal tem efeitos nocivos, nem todos evidentes. Tal como afirmam Bourdieu e Wacquant (2013), termos como empregabilidade (e outros que parecem circular sem origem definida e em uma falta de historicidade preocupante) têm efeitos poderosos porque reconstroem "o mundo fazendo tábua rasa das conquistas sociais e econômicas resultantes de cem anos de lutas sociais, descritas como arcaísmos e obstáculos à nova ordem nascente" (BOURDIEU \& WACQUANT, 2013, p. 82). O conceito de empregabilidade insiste na individualização, ficando ausentes da discussão termos como capitalismo, classe, exploração, desigualdades, ou tantos outros que canalizariam a discussão para a estrutura e seus efeitos como constrangimento das escolhas dos indivíduos, mas também como mecanismo de reprodução das desigualdades societais. Também Brown, Hesketh e Wiliams (2003) defendiam que a empregabilidade individual culpabiliza as vítimas, nesse caso os estudantes do ES e os graduados, que corriam o risco de internalizar como suas as responsabilidades pelo insucesso na inserção profissional. Ora, não é possível advogar que os graduados devem ser objetos, moldáveis às rápidas e numerosas flutuaçōes do mercado de trabalho. E como afirmam os autores anteriormente citados, um indivíduo pode ter condiçóes individuais para ser empregável mas, ainda assim, o mercado não lhe apresentar oportunidades para ser bem-sucedido. 
É nessa lógica que situamos a reflexão sobre a responsabilidade das IES na promoção da empregabilidade.

\section{A responsabilidade do ensino superior na promoção da empregabilidade}

A primeira questão que deve ser colocada é se o ES é, de fato, o melhor espaço para se desenvolver a empregabilidade. Se atentarmos apenas aos conceitos dominantes, centrados nos indivíduos e na sua formação acadêmica, parece não haver grandes dúvidas. Mas esse conceito é excessivamente redutor e ignora as responsabilidades das políticas públicas, Estados e governos, para não falar dos empregadores. Alguns autores têm chamado a atenção para os reducionismos da empregabilidade como conceito dominante. Guilbert et al. (2016) defendem, por isso, que é preciso construir um novo conceito de empregabilidade que inclua uma série de dimensóes e que as IES deveriam exigir uma responsabilidade partilhada pela empregabilidade, pelo menos com o estado e os empregadores.

Mas ainda que advoguemos que o ES pode promover a empregabilidade, não é líquido que o deva fazer à luz das suas missóes e funçóes. Em primeiro lugar, é pertinente recordar que o ES não é homogêneo. Inclui instituiçôes muito diferentes no que diz respeito, por exemplo, à sua missão (universitário versus politécnico), dedicação à investigação/ensino, formas de gestão, natureza nacional/ internacional etc. A forma como cada IES assume os seus objetivos não é indiferente. McCowan (2015) recorda-nos que existem três posições principais que podem, potencialmente, ser tomadas:

- o ES deve ter um valor apenas intrínseco;

- o ES pode, adicionalmente, ter um valor instrumental, mas apenas se os objetivos instrumentais foram válidos;

- o ES pode promover qualquer objetivo instrumental, tanto definido por indivíduos, como pela sociedade.

A promoção da empregabilidade é muito mais baseada em fatores externos do que no valor prático intrínseco à própria academia. Ante a diversidade dos sistemas de ES e a disparidade das IES que o integram, é difícil dar uma resposta cabal a essa questáo. O que podemos dizer é que a resposta de se o ES deve promover a empregabilidade deve ser fruto de um debate sério, alargado e democrático.

Outros temas se levantam a propósito dessa questão. Alguns autores têm sugerido que a empregabilidade pode ser mais facilmente desenvolvida fora do curriculum formal (YORKE, 2004b), como acontece com as experiências de 
formação no posto de trabalho, programas desenvolvidos em parceria entre IES e empregadores, ou estágios nas suas várias formas. Afinal, as regras básicas do mundo do trabalho, as culturas laborais de cada empresa ou instituiçáo ou os valores que as orientam, são muito mais familiares aos empregadores do que à academia. E essa posição admite formulações mais extremas ou mais cooperativas. É possível separar totalmente a função formativa de uma outra, mais instrumental, relacionada com o desenvolvimento da empregabilidade. Mas podem, como alternativa, organizar programas conjuntos em que os empregadores têm uma presença física nos campi-e as duas opçôes simultâneas não só são possíveis, como até já fazem parte das práticas cotidianas de muitas IES.

A natureza das relaçóes entre as IES e os empregadores é condição para a definição de um caminho estratégico para a promoção da empregabilidade mas, também, para muitas outras dimensōes que afetam os respetivos setores. A esse propósito, alguns investigadores assumem posicionamentos extremos: segundo Tymon (2011), para alguns acadêmicos as instituiçóes de ES não devem formar os graduados para o emprego pois essa seria uma função exclusiva dos empregadores; Moreau e Leathwood (2006) chegam mesmo a afirmar que o foco crescente no desenvolvimento de competências pode ameaçar a liberdade acadêmica.

É preciso notar que, frequentemente, se assume como razoável que seja o ES a chamar a si a tarefa de desenvolver competências para melhorar a empregabilidade dos estudantes. Mas o desenvolvimento de competências se reveste de certa complexidade e dificilmente podemos assumir que a vida dos estudantes se esgota nos espaços e tempos educativos de uma universidade. Para McCowan (2015, p. 278), "nenhum dos atributos genéricos associados à empregabilidade escrita e comunicação oral, pensamento crítico, trabalho em equipe, resolução de problemas e assim por diante - é exclusivamente do domínio do ensino superior". São desenvolvidos de forma gradual, durante todo o percurso escolar e em outras esferas da vida, normalmente extraescolares.

A clareza dessa ou de outras posiçóes semelhantes suporta o nosso argumento central: apesar do momento histórico que vivemos e das pressóes a que o ES parece estar sujeito, seja pelos governos, pelos empregadores ou outros grupos sociais, a academia pode e deve discutir essas questōes substantivas. Na nossa opinião, algumas dessas posições podem ser tomadas como elitistas, outras como uma tentativa de manter a academia longe de uma certa forma de vocacionalismo hoje influente e outras, ainda, como uma tentativa de recusar uma certa confusão entre o ES e o mercado.

Sin e Amaral (2017), por exemplo, em um estudo recente, avaliaram em que medida o ES pode ser considerado responsável por desenvolver a empregabilidade. Os autores perceberam que o ES é considerado, nas perceçôes dos acadêmicos e dos empregadores participantes no estudo, como o agente principal responsável pelo desenvolvimento da empregabilidade dos estudantes. Contudo, os 
resultados revelam níveis modestos de atividades realizadas para melhorar a empregabilidade e um baixo nível de cooperação entre as IES e os empregadores.

A verdade é que permanecem dúvidas relativamente ao que pode o $\mathrm{ES}$ fazer, mesmo que queira, para melhorar a empregabilidade dos graduados. Nas palavras de Tomlinson (2007, p. 303):

As universidades podem, de fato, ser limitadas na sua capacidade de melhorar a empregabilidade dos seus estudantes, mesmo que os decisores políticos continuem a argumentar que elas têm um papel fundamental. As políticas de ensino e aprendizagem em torno da empregabilidade dos graduados podem ter, apenas, um impacto mínimo no apoio às trajetórias dos graduados no mercado de trabalho.

\section{Metodologia}

Para conhecer as perceçóes de estudantes, graduados, empregadores e acadêmicos sobre a responsabilidade do ES relativa à empregabilidade, recorremos à investigaçáo qualitativa (DENZIN \& LINCOLN, 1998). Realizamos, ao todo, 64 entrevistas não-estruturadas (RUIZ, 1999): 21 estudantes que frequentam o último ano das suas licenciaturas ou mestrados (10 voltaram a ser entrevistados um ano depois, para tentarmos compreender as alteraçóes verificadas); 10 graduados de áreas científicas distintas, com um mínimo de três anos de experiência laboral; 13 empregadores dos setores econômicos mais representativos na região; e 10 membros da comunidade acadêmica (diretores de curso, representantes dos serviços relacionados com empregabilidade e da reitoria). As entrevistas foram transcritas e analisadas recorrendo a uma codificação temática (BARDIN, 1991) emergente: não foram realizadas codificaçóes prévias, mas pretendemos interpretar as categorias emergentes (KONDRACKI; WELLMAN; AMUNDSON, 2002) no sentido de descobrir padrōes de significado, usando-se um procedimento indutivo.

\section{Resultados: as perceções dos empregadores, graduados e academia}

Apenas uma minoria dos empregadores (EMP) que entrevistamos pensam que a empregabilidade deve ser compreendida em uma perspetiva ampla, sendo responsabilidade partilhada dos indivíduos, empregadores, IES, políticas, governos, dinâmicas familiares ou educação não-superior. Contudo, para a maioria dos empregadores, ela está fortemente relacionada com o posicionamento dos 
graduados face ao mercado de trabalho, características pessoais e competências que que são capazes de mobilizar. Nessa lógica, a responsabilidade pela empregabilidade recairia, sobretudo, nos graduados.

Os estudantes e graduados (GRAD) que entrevistamos estão globalmente de acordo com os empregadores. Para eles, a empregabilidade é uma construçấo individual, baseada nas competências e nas qualidades pessoais que possuem. Existe, no entanto, uma minoria que considera serem importantes as condiçóes do mercado de trabalho (como o clima econômico ou políticas e procedimentos de contratação).

Os representantes da comunidade acadêmica (ACAD) perspetivam o conceito de forma diferente. Enfatizam o problema do desemprego, as dinâmicas da economia nacional e regional e as dinâmicas próprias do mercado de trabalho (incluindo a precariedade, sazonalidade etc.), para afirmar que a empregabilidade depende, primariamente, desses macro fatores impossíveis de controlar a partir do ES:

Eu não tenho muitas ilusôes. Os desempenhos [na empregabilidade] sáo sempre muito condicionados pelos contextos e se a regiáo estiver a criar emprego entáo os nossos diplomados terão mais facilidade em encontrar emprego. Em dezembro de 2013 a Universidade estava no indicador de empregabilidade, facultado pelo Ministério, creio que em 16ㅇ em 2014 subimos para $9^{\circ}$; ainda não conhecemos os dados de 2015, mas eu diria que vamos subir mais 2 ou 3 posiçóes. Ora, se em dois anos passamos de $16^{\circ}$ para $6^{\circ}$ ou $7^{\circ}$, não foi pelas políticas da Reitoria nem do Vice-Reitor, foi pela conjuntura da atividade econômica $(A C A D)$.

A responsabilidade pela empregabilidade não deveria, na perspetiva dos representantes da comunidade acadêmica, ser exclusivamente atribuída ao ES. As entrevistas com o staff acadêmico revelaram outras preocupaçóes: a universidade deve estar atenta às necessidades e especificidades do mercado de trabalho para, assim, poder alterar ou melhorar a formação dos seus estudantes? Em que medida deve estabelecer relaçôes mais próximas com os empregadores?

A lista de competências mais importantes para os empregadores é, de fato, muito grande: pró-atividade, vontade para trabalhar, motivação para desempenhar a funçáo, capacidade de aprendizagem e de adaptaçáo ao meio organizacional, flexibilidade para realizar várias tarefas distintas, dedicação, capacidade de inovar e disponibilidade, entre outras. Para os empregadores entrevistados, o diploma universitário é apenas um requisito para a candidatura ao emprego, mas não é uma característica diferenciadora que, por si, dite a contratação:

Muitas vezes as pessoas confundem os estudos, o conhecimento, com a empregabilidade. Uma coisa náo tem necessariamente que ver com a outra. Eu não posso sair da universidade, só por- 
que sou licenciado, e achar que vou ser Diretor Hoteleiro. [...] Náo é pelo fato de termos estudado e de termos um mestrado que temos de ir logo para uma posição de chefia $(E M P)$.

Também para os estudantes e graduados, o valor do diploma é relativo e as competências individuais e qualidades pessoais parecem ser mais importantes. No discurso dos graduados não há nenhuma preocupação explícita na classificação das competências, mas conhecem bem a direção dos interesses dos empregadores:

Uma pessoa que seja polivalente [risos]. Que faça tudo. Uma pessoa que seja de boas relaçóes, que se integre facilmente numa empresa, numa instituição, numa associação. Uma pessoa que tenha boas relaçóes, que náo crie conflitos, que seja uma pessoa empenhada, dedicada ao trabalho, que trabalhe muito, muito, muito, muito! É o que, nesta altura, eles procuram. Uma pessoa que faça o trabalho de várias pessoas e que seja flexível [...] me é exigido que faça tarefas que não têm a ver necessariamente com a minha formação. Cada vez mais $(G R A D)$.

Uma minoria entre os graduados acha que os empregadores procuram um perfil quase inatingível. Requer-se que um graduado esteja em um estado de permanente prontidão e que seja flexível ao ponto de fazer o que há para fazer, quando e como é preciso fazer, pela perspetiva única das necessidades do empregador. Essa minoria acredita que isto pode ser chamado exploração.

Os acadêmicos acreditam que, apesar da importância das competências técnicas, outro lote de competências é mais procurado pelos empregadores: responsabilidade; disponibilidade para aprender, para a mudança e adaptação aos contextos de trabalho; compreender métodos e regras de trabalho; capacidade de trabalhar em equipe; e sentido de compromisso, bom senso. Também é maioritária a opiniáo de que o desenvolvimento de competências transversais não está apenas dependente do ES. A família, os pares e todo o processo educativo até a universidade definem a formação e o desenvolvimento pessoal do indivíduo. Assim, as IES devem preparar os estudantes, civicamente, para responder aos desafios da sociedade. E para isso, o foco deve estar nas competências que permitirão aos graduados resolver problemas para, de forma crítica, criarem métodos de trabalho que lhes permitam inserir-se e adaptar-se aos contextos laborais.

Os empregadores acham que, a somar às responsabilidades dos graduados, também as IES têm uma importante quota-parte de responsabilidade no desenvolvimento da empregabilidade. No geral, os empregadores consideram que as relações existentes com a academia são pouco frequentes e pouco eficientes. Um número significativo de empregadores diz recorrer às IES quando precisa recrutar estudantes para estágios ou para trabalhar, por meio de canais de comunicação diversos: professores com quem já colaboraram, serviços, reitoria. Os em- 
pregadores referem, ainda, que as ligaçóes que existem com a academia advêm de relaçóes pessoais ou da rede de contatos.

Também os estudantes e graduados consideram que a relação entre a academia e os empregadores não é satisfatória. A maioria dos graduados refere uma nítida falta de articulação entre esses dois mundos. Embora haja uma tendência geral para responsabilizar a universidade pelo fato, também há quem diga que não sabe em qual dos lados está a culpa.

Os acadêmicos têm a perceção de que esses dois mundos estão distantes. Mas contrariamente aos outros grupos, interrogam-se sobre se esses dois mundos não deveriam, de fato, estar separados, considerando a missão e as funções principais das IES e a separação, que deveria existir, entre a academia e o mercado:

Parece-me que a universidade e os empregadores não estão assim tão próximos... nem sei se deviam estar. Eu não sei. Eu estive na Holanda, inserido no ambiente universitário, e essa relação não existia [...]. A questão do trabalho e do emprego é uma questão social que ultrapassa a universidade. A funçáo da universidade é formar bem, estar up-to-date. Se o mercado de trabalho não tem dinâmicas, a universidade náo pode substituir o mercado de trabalho. Eventualmente os estágios, sim, isso me parece bem, mas nunca chegarmos ao ponto de a universidade ficar refém de, para além de formar, ter que empregar, porque a universidade não é um centro de emprego $(A C A D)$.

Como caracterizam, os empregadores, as relaçôes ideais a manter com a academia? Defendem uma bolsa de emprego ativa, estruturada, que consiga dar resposta às necessidades dos empregadores. Consideram que seria importante uma interação constante, por meio de uma estrutura organizada, nas IES, com profissionais de recursos humanos. Essa estrutura deveria contatar frequentemente com o mercado de trabalho, mas também com os professores, de forma a identificar estudantes capazes de preencher determinadas ofertas de trabalho. Ou seja, os empregadores veem as suas relaçóes com a universidade em função, apenas, das necessidades das suas empresas ou instituições.

É exatamente nessa questão que as posiçóes entre acadêmicos e empregadores se extremam. A comunidade acadêmica afirma estar a serviço das sociedades - mas não estar, de forma nenhuma, ao serviço do mercado e, portanto, dos empregadores:

Não só se está a mudar o foco, como se exige que as Universidades se tornem agências de emprego, o que é profundamente injusto e não tem nada a ver com a vocação das universidades. Mas pior ainda, estão a fazer pressão para que as universidades modifiquem as suas formaçôes no sentido de satisfazer o mercado de trabalho. Ora eu aceito, e isto é novamente uma questão ideológica, que haja uma dimensão da formação uni- 
versitária que quer dar resposta aos desafios societais. Mas não é aos desafios do mercado de trabalho, é aos desafios da sociedade. Pode-se perguntar que tipo de competências é que a sociedade vai necessitar no futuro, mas isto não é o tipo de competências que as empresas vão necessitar amanhã ou depois $(A C A D)$.

A formação superior, em si, é um tema que divide os nossos entrevistados. A maioria dos empregadores considera que os graduados chegam ao mercado de trabalho mal preparados (à exceção dos empregadores do $3^{\circ}$ setor). Os empregadores consideram que há um fosso grande entre os conhecimentos que os graduados possuem e a sua capacidade para aplicá-los em contextos reais de trabalho e que os graduados têm uma grande falta de maturidade. Os empregadores acreditam que isso reflete a fraca aposta que as IES fazem para desenvolver as competências pessoais e sociais dos estudantes e que os currículos acadêmicos incluem poucas questóes comportamentais (comunicação, liderança, trabalho em equipe, aprender a colocar-se no lugar do outro, assertividade etc.).

Eu quando olho para os currículos dos diversos cursos, nas Faculdades, nas universidades, vejo, normalmente, muito poucas matérias, muito pouco tempo dedicado a estes temas, dedicado a temas como liderança, comunicação, todas estas áreas de liderança e gestão de pessoas... As universidades devem conseguir trabalhar esta vertente emocional, de liderar, de responsabilização, de gestão de pessoas, comunicar. E quando eu digo comunicar não são os processos comunicacionais, é perceber que se calhar primeiro tem que ouvir para depois poder comunicar. Isto são temáticas que se deviam colocar nos currículos dos cursos $(E M P)$.

Os estudantes e graduados também questionam os currículos, defendendo que deveriam estar mais adaptados às necessidades do mercado de trabalho. $\mathrm{Na}$ sua opinião, as IES deveriam entender o que está passando no mundo do trabalho e procurar uma maior adequação à prática. Apenas uma minoria nota que o mercado tem dinâmicas de ritmo e natureza diferente:

"Também não é dirigir tudo para o mercado de trabalho, porque o mercado de hoje para a amanhã muda, mas há coisas que são core, que são fundamentais, e a Universidade tem que estar sempre constantemente atenta a essas coisas" (GRAD).

Para os graduados, muito se poderia conseguir com uma série de atividades extracurriculares que, embora pudessem ser feitas e organizadas a partir das IES, teriam a vantagem de aproximar os graduados do mundo do trabalho, melhorando o seu conhecimento acerca da cultura do trabalho e dos seus potenciais empregadores: organização de programas conjuntos com empregadores, cursos, oficinas, participação em projetos, sessóes de esclarecimento, visitas às empresas etc. 
Os acadêmicos são contra a perspetiva de que os empregadores devem influenciar o currículo, o conteúdo dos cursos ou a forma como as IES formam os seus estudantes. As necessidades dos empregadores são tão diversas quanto específicas e olham apenas para o presente. Nesse sentido, a academia não deveria formar graduados atendendo a perfis conjunturais:

A minha perspetiva é que nós não podemos estar formando os jovens para irem trabalhar para a empresa A ou B nos próximos seis meses. Haverá sempre aqui um desfasamento entre o que as empresas querem e o trabalho das universidades. É relativamente fácil uma empresa dizer "a universidade não está formando as pessoas que eu quero". Possivelmente, daqui a três anos essa empresa poderá já nem existir $(A C A D)$.

Não é o papel da universidade estar permanentemente ajustando as suas formaçôes à necessidade, que é conjuntural, dos empregadores. Repare, se um empregador precisa de alguém agora que desenvolva uma aplicação de smartphone, daqui a 10 anos não vai haver smartphones, vai haver outra coisa qualquer e essa competência tornou-se completamente obsoleta $(A C A D)$.

As relaçôes entre staff acadêmico e empregadores incluem, ainda, um conjunto de tensōes relevantes. Parecem, realmente, dois mundos ainda distantes:

São dois mundos completamente diferentes e cada vez percebo mais disso. Eu acho que as universidades continuam muito acadêmicas, muito teóricas, e as empresas continuam muito práticas. E, apesar de haver um esforço para juntar o ensino às empresas, não tem sido suficiente. Trata-se apenas de açôes pontuais, açôes para cumprir calendário, ou açôes para mostrar ao governo, ou para mostrar a alguém que, de fato, se está a fazer esse trabalho, mas que na prática está difícil $(E M P)$.

O cerne da questão, todavia, está em compreender as dificuldades de estudantes e graduados. Se há algo que merece unanimidade entre os três grupos entrevistados é justamente nesse ponto: as transiçōes do ES para o emprego são difíceis e, atualmente, são poucas as iniciativas dirigidas aos estudantes que apoiem essas transiçóes. Todos concordam que seria importante criar uma estrutura profissional dedicada a essa tarefa, congregando serviços já existentes, mas fragmentados, e criando novos serviços.

Tem de haver uma estrutura da própria universidade com profissionais a sério, dentro da área da empregabilidade, trabalhando com os estudantes e com os licenciados. Acho que seria importante haver um acompanhamento dos licenciados no mercado 
de trabalho porque eles, quando acabam, são largados. São largados! A transição náo acontece. $\mathrm{O}$ ponto chave seria existir uma interação entre os professores ou técnicos da universidade e os empregadores [...]. Mas, temos que ter profissionais que trabalhem nessa área e que tenham um grande conhecimento do mercado de trabalho e que possam fazer esta ligaçáo e este contato permanente $(A C A D)$.

\section{Discussão e conclusão}

À semelhança dos resultados da investigação de Sin e Amaral (2017), os nossos dados demonstraram que as IES são tendencialmente consideradas como responsáveis pela empregabilidade; o Estado e a política são referidos como responsáveis apenas por uma minoria; e o nível de cooperação efetiva, entre acadêmicos e empregadores, é reduzido. Não obstante, os dados qualitativos fornecem outras explicações, mais profundas - nunca generalizáveis — de que os dados quantitativos não almejam fornecer.

Percebemos que o conceito de empregabilidade de empregadores, estudantes e graduados (contrariado pelo representantes da comunidade acadêmica) é muito semelhante: como responsabilidade individual dos graduados, que devem construir um leque de competências individuais e qualidades pessoais adequadas às empresas e instituiçóes, em uma aproximação às concetualizações de Hillage e Pollard (1998), ou Yorke (2004a; 2004b), entre outros. A situação demonstra um consenso peculiar: os antigos discursos de emprego e desemprego, discutidos à luz das Ciências Sociais críticas e no contexto do estado-providência, parecem ter sido substituídos pelos da empregabilidade, não histórica e desenraizada das descobertas dos últimos anos das Ciências Sociais, típica de políticas neoliberais. Os próprios estudantes internalizaram um conceito que os culpabiliza e os obriga a serem objetos moldáveis às necessidades do mercado de trabalho, que não reconhece as responsabilidades sociais dos seus agentes. Nessa situação, não é de estranhar que a responsabilidade pela empregabilidade seja, maioritariamente, outorgada ao ES. Como vimos, no entanto, os acadêmicos resistem a essa questão. Mas enquanto na investigação de Sin e Amaral (2017) o fato é atribuído a uma assunção ambígua ou incompleta do processo de Bolonha por parte dos acadêmicos, os nossos resultados parecem revelar motivos mais profundos para essa resistência.

O necessário diálogo entre a academia e os empregadores parece estar ainda em uma fase exploratória. Muitos temas terão que ser discutidos abertamente entre os seus atores sociais: as funçóes, missōes e objetivos dessas organizaçôes, a responsabilidade perante os graduados ou a responsabilidade social sáo apenas alguns exemplos. À nossa frente estende-se um longo caminho, antes de os próprios empregadores se assumirem como stakeholders das IES - tentativa, 
aliás, introduzida pelo próprio RJIES durante a implementação do processo de Bolonha. Acreditamos que só a partir dessa discussão prévia representantes da comunidade acadêmica e empregadores poderão aspirar a construir uma cooperação mais frutuosa.

Recuperando as contribuiçóes de McCowan (2015) a propósito dos objetivos e valor da academia, o nosso estudo revelou uma comunidade acadêmica que náo nega objetivos instrumentais, estando preparada para uma discussão mais profunda sobre esses mesmos objetivos que não assume como seus, automaticamente. Tornou-se claro, para nós, que a comunidade acadêmica quer traçar uma linha de separação, a vários níveis, entre aquilo que é o serviço público ou as suas responsabilidades para com os estudantes, e o mercado de trabalho. Mas aceita como válido o objetivo instrumental de organizar um serviço que possa apoiar os estudantes nas suas transiçōes para o mercado de trabalho. O futuro o dirá.

\section{Agradecimentos}

Este artigo é financiado por Fundos Nacionais através da Fundação para a Ciência e a Tecnologia (FCT) no âmbito do projeto UID/SOC/04020/2013, e também por meio da Bolsa SFRH/ BD/132068/2017.

\section{Nota}

1. Projeto 2014-1-UK01-KA203-001842-T, financiado pelo programa Erasmus+, Enhancing the employability of non-traditional students in Higher Education (EMPLOY). Instituição coordenadora: Universidade de Warwick. Instituiçóes parceiras: Universidade do Algarve (Portugal), Universidade da Lower Silesia (Polônia), Universidade de Estocolmo (Suécia), National University of Maynooth (Irlanda), Universidade de Sevilha (Espanha).

\section{Referências}

ALVES, N. E se a melhoria da empregabilidade dos jovens escondesse novas formas de desigualdade social? Sísifo, v. 2, p. 59-68, 2007.

ALVES, N. Inserção profissional e formas identitárias. Lisboa: Educa, 2009.

BARDIN, L. Análise de Conteúdo. Lisboa: Ediçōes 70, 1991.

BOURDIEU, P.; WACQUANT, L. O imperialismo da razão neoliberal. Sociologia em Rede, v. 3, n. 3, p. 82-87, 2013.

BROWN, P.; HESKETH, A. The mismanagement of talent: employability and jobs in the knowledge-based economy. Oxford: Oxford University Press, 2004. 
BROWN, P.; HESKETH, A.; WILIAMS, S. Employability in a Knowledge-driven Economy. Journal of Education and Work, v. 16, n. 2, p. 107-126, 2003. http://doi. org/10.1080/1363908032000070648

CABRITO, B. G. O financiamento do ensino superior em Portugal: Entre o Estado e o mercado. Educaçáo e Sociedade, v. 25, n. 88, p. 977-996, 2004.

CHAVES, L.; GAIO ALVES, M. Inserçáo profissional de diplomados em Portugal: sistematizaçáo das metodologias utilizadas nas universidades e construçáo de um guiáo-modelo para colecta de dados a nível nacional. Projeto em curso financiado pela FCG. 2014.

DENZIN, N. K.; LINCOLN, Y. S. Entering the Field of Qualitative Research. In: DENZIN, N. K.; LINCOLN, Y. S. (orgs.). Collecting and Interpreting Qualitative Materials. Thousand Oaks: Sage Publications, 1998. p. 1-34.

EUROPEAN COMMISSION. Eurydice Report. Modernisation of Higher Education in Europe: Access, Retention and Employability. Bruxelas: European Commission, 2014.

FIELD, J. Social capital. Londres: Routledge, 2004.

GAIO ALVES, M. Contributos para pensar a regulação entre educação, trabalho e emprego. In: GAIO ALVES, M. (orgs.). Universidade e Formaçáo ao Longo da Vida. Lisboa: Celta, 2008. p. 67-90.

GUILBERT, L.; BERNAUD, J. L.; GOUVERNET, B.; ROSSIER, J. Employability: review and research prospects. International Journal for Educational and Vocational Guidance, v. 16, n. 1, p. 69-89, 2016. http://doi.org/10.1007/s10775-015-9288-4

HILLAGE, J.; POLLARD, E. Employability: Developing a framework for policy analysis. 1998. Disponível em: <http://www.employment-studies.co.uk/report-summaries/reportsummary-employability-developing-framework-policy-analysis $>$. Acesso em: 2 out. 2017.

KONDRACKI, N. L.; WELLMAN, N. S.; AMUNDSON, D. R. Content analysis: Review of methods and their applications in nutrition education. Journal of Nutrition Education and Behavior, n. 34, p. 224-230, 2002. https://doi.org/10.1016/S1499-4046(06)60097-3

LIVINGSTONE, D. W. The Limits of Human Capital Theory: Expanding Knowledge, Informal Learning and Underemployment. Policy Options, v. 18, n. 6, p. 9-13, 1997.

MAYHEW, K.; KEEP, E. The Assessment of Knowledge, Skills and Competitiveness. Oxford Review of Economic Policy, v. 15, n. 1, p. 1-15, 1999. https://doi.org/10.1093/ oxrep/15.1.1

MCCOWAN, T. Should universities promote employability? Theory and Research in Education, v. 13, n. 3, p. 267-285, 2015.https://doi.org/10.1177\%2F1477878515598060

MOREAU, M. P.; LEATHWOOD, C. Graduate's employment and the discourse of employability: a critical analysis. Journal of Education and Work, v. 19, n. 4, p. 305-324, 2006. https://doi.org/10.1080/13639080600867083 
MORGADO, J. C. Processo de Bolonha e ensino superior num mundo globalizado. Educaçáo e Sociedade, v. 30, n. 106, p. 37-62, 2009. http://dx.doi.org/10.1590/S0101$\underline{73302009000100003}$

RUIZ, J. I. Metodología de la investigación cualitativa. Bilbao: Universidad de Deusto, 1999.

SARRICO, C.; ROSA, M.J.; TEIXEIRA, P.; MACHADO, I.; BISCAIA, R. A Eficiência Formativa e a Empregabilidade no Ensino Superior Português. Lisboa: A3ES, 2013.

SCHULTZ, T. W. Investment in Human Capital. The American Economic Review, v. 51, n. 1, p. 1-17, 1961.

SIN, C.; AMARAL, A. Academics' and employers' perceptions about responsibilities for employability and their initiatives towards its development. Higher Education, n. 73, p. 97-111, 2017. https://doi.org/10.1007/s10734-016-0007-y

TOMLINSON, M. Graduate employability and student attitudes and orientations to the labour market. Journal of Education and Work, v. 20, n. 4, p. 285-304, 2007. https:// doi.org/10.1080/13639080701650164

TOMLINSON, M. “The degree is not enough”: students' perceptions of the role of higher education credentials for graduate work and employability. British Journal of Sociology of Education, v. 29, n. 1, 49-61, 2008. https://doi.org/10.1080/01425690701737457

TYMON, A. The student perspective on employability. Studies in Higher Education, v. 38, n. 6, p. 841-856, 2011. https://doi.org/10.1080/03075079.2011.604408

YORKE, M. Employability in higher education: what it is - what it is not. York: The Higher Education Academy/Enhancing Student Employability Co-ordination Team, 2004a. (Learning and Employability Guides.) Disponível em: < http://www.employability.ed.ac.uk/ documents/Staff/HEA-Employability in HE(Is,IsNot).pdf > . Acesso em: $1^{\circ}$ out. 2017.

YORKE, M. Employability in the undergraduate curriculum: Some student perspectives. European Journal of Education, v. 39, n. 4, p. 409-427, 2004 b.

YORKE, M.; KNIGHT, P. T. Embedding employability into the curriculum. York: Higher Education Academy, 2006. Disponível em: <http://qualityresearchinternational. com/esecttools/esectpubs/Embedding employability into the curriculum.pdf $>$. Acesso em: $1^{\circ}$ out. 2017.

Recebido em 16 de outubro de 2017.

Aceito em 10 de setembro de 2018.

(C) 2019 Centro de Estudos Educação e Sociedade - CEDES Este é um artigo de acesso aberto distribuído nos termos de licença Creative Commons. 